\title{
CONVIVÊNCIA INTEGRAL E APRENDIZADOS NA TELA: UMA ANÁLISE DE LIVES SOBRE PARENTALIDADES EM TEMPOS DE COVID
}

\author{
Anna Paula Uziel (UERJ - uzielap@gmail.com) \\ Roberta Gomes Nunes (UERJ e TJRJ - robynunes@gmail.com) \\ Rayanne Suim Francisco (UERJ - rayannesuim@ gmail.com) \\ Renata Gonçalves Roma (UERJ - renata.roma@hotmail.com) \\ Larissa Pinto Moraes (UERJ - larissap_morais@ @otmail.com) \\ Ludmilla Furtado da Silva (UERJ - ludmillafurtados@gmail.com) \\ Marcello Furst de Freitas Accetta (UERJ - marcelloffaccetta@gmail.com) \\ Maria Clara de Mello Andrade (UERJ - mariamelloandrade@ hotmail.com) \\ Amanda Neves Rastrelli (UERJ - rastrelli.amanda@gmail.com) \\ Camila Tomé da Silva (UERJ - camilats.psi@gmail.com)
}

\begin{abstract}
RESUMO
Esse trabalho tem como objetivo fazer uma análise das expressões e sentidos que profissionais, mães e pais vêm dando aos diferentes exercícios da parentalidade em tempos de confinamento, como efeito da crise pandêmica que vivemos no Brasil em decorrência do novo coronavírus. Por meio da análise de 26 vídeos, distribuídos entre lives e vídeos curtos disponíveis na plataforma do Youtube, escolhidos a partir do cruzamento dos termos parentalidade e pandemia, propusemos o desafio de pensar o exercício da parentalidade em relações de convívio das famílias com crianças e adolescentes. Nossa proposta era entender como adultos e crianças da família que convivem no mesmo espaço neste momento de pandemia, em suas diversas configurações e condições, têm experimentado o tempo, marcado pela ausência de intermitência, com o convívio praticamente ininterrupto com elas. Muitas famílias de camadas médias e altas se depararam, pela primeira vez, com a necessidade de cuidado integral de sua prole, que em geral é dividido com escola, babás, empregada doméstica, além de avós. Foi possível notar que embora as crianças sejam parte fundamental da trama e muitos dos questionamentos se façam a partir da presença permanente delas em casa, nenhuma das lives que apareceram no Youtube tem a participação das mesmas ou trata das suas percepções sobre os tempos de confinamento. Nota-se também uma certa homogeneidade das pessoas que proferiram as lives em termos de classe social, região do país e profissão, sendo basicamente mulheres brancas de camadas médias das regiões sul e sudeste do país, psicólogas e pedagogas. As famílias para as quais as lives se dirigem são formadas por casais cis, heterossexuais, brancos, de camadas médias e altas, sem que essas características sejam sequer apontadas. A perspectiva interseccional não aparece.
\end{abstract}

Palavras-chave: parentalidades; youtube; pandemia global

\section{INTEGRAL CONVIVIALITY AND LEARNING ON SCREEN: AN ANALYSIS OF LIVE STREAMINGS ON PARENTHOOD IN TIMES OF COVID}

\begin{abstract}
This research aims to analyze the expressions and meanings that professionals, mothers and fathers have been giving to different parenthoods in times of confinement, as an effect of the pandemic crisis in Brazil due to the new coronavirus. Through the analysis of 26 videos (live streaming and short videos) available on YouTube and chosen by crossing the terms "parenthood" and "pandemic" our reasoning is related to the parenthood in a context of families with children and teenagers. The research aims to understand how adults and children
\end{abstract}




\section{Nanduty}

ISSN:2317-8590

coexisting in a context of pandemics have experienced an uninterrupted conviviality. Our results show that many families from the middle and upper classes have been faced, for the first time, with of an integral care of their offspring, which is usually shared with school, nannies, housekeepers, and grandparents. Although children are a fundamental part of parents' lives and their presence at home is permanent during the pandemics, none of the live streaming analyzed have their participation or dealt with their perceptions about the times of confinement. There's also a pattern of people into the live streaming regarding social class, geographical region and profession - basically white middle-class women from the South and Southeast regions of the country, psychologists, and pedagogues. The families to which the live streaming is directed are made up of cis, heterosexual, white, middle class, and upper-class couples, although such characteristics have never being pointed out. The intersectional perspective does not appear.

Keywords: parenthood; YouTube; global pandemic

\section{INTRODUÇÃO}

O presente trabalho propõe discutir o exercício da parentalidade durante a pandemia de COVID-19, a partir de uma cartografia de lives e vídeos curtos, dispositivos que nos acompanham intensamente este período. Em um país fortemente marcado pelas desigualdades sociais, a vivência da pandemia tem essa marca em todos os seus aspectos. Neste artigo, nossas análises consideram apenas camadas médias urbanas das grandes cidades, que ocupam tanto o lugar de palestrantes, como o público para o qual se dirigem - ainda que se conheça sua não homogeneidade. Foram e são as camadas mais abastadas da população que puderam se manter em casa, fazendo home office e com as escolas de suas crianças e adolescentes funcionando a partir de determinado momento.

As regras de isolamento físico impostas como medida de segurança concentraram no espaço doméstico e virtual atividades até então setorizadas em ambientes específicos como a escola, a universidade, o trabalho e espaços de convivência, lazer, cultura e interação social. Este texto, escrito nos meses de outubro a dezembro de 2020, é uma intervenção a quente, as linhas no computador apareciam enquanto nossos olhos se acostumavam com horas na frente das telas. Algumas de nós, mães de crianças e adolescentes.

A interrupção de uma série de eventos extra domésticos, como a escola das crianças e dos adolescentes e o trabalho de pais, mães e familiares, bem como sua realocação para dentro de casa, através do meio virtual, conjugadas ao aumento abrupto do convívio entre os membros da família nuclear tendem a transformar as relações, que são experimentadas sem intermitência, com frequência pela primeira vez. 


\section{Nanduty}

ISSN:2317-8590

No Brasil, a pandemia é nova para todas as pessoas, de todas as gerações, idade, gênero, cor de pele, localidade. Neste aspecto ela é a mesma, ainda que em todos os outros as desigualdades que nos constituem sejam exacerbadas.

O mundo através das telas impõe novos desafios, sobretudo para os grupos que compartilham de um mesmo espaço físico, ao buscarem arranjos e conciliações para comportar esses múltiplos eventos em um único lugar. Neste contexto, as lives ocupam um espaço significativo na produção e difusão de conhecimento, compartilhamento e troca de ideias, que temos aprendido a fazer através da tela do computador, celular e outros dispositivos eletrônicos. As lives são transmissões que fazem ranger nossa concepção de "à distância", propondo debates entre palestrantes em 2D e uma plateia igualmente remota, às vezes conhecida, outras, desconhecida, e sem controle de presença ou ideia da atenção que dispensa. Às vezes é possível ter algum retorno simultâneo pelo chat, mas frágil.

Dependendo dos canais de divulgação, o alcance pode ser inesperado, desenhando um público que, em princípio, pode se diferenciar, em muito, daquele que se deslocaria para ouvir determinada fala. As pessoas que fazem a live pertencem a grupos organizados, movimentos sociais, associações científicas, profissionais liberais de todas as áreas, independentes, ou quem simplesmente acredite ter algo a dizer, em qualquer campo da vida, o que muda um pouco o perfil de quem se autoriza ou é autorizado a falar, colocando em análise a concepção de especialista.

Assim, temas diversos passaram a ser debatidos e expostos neste modelo marcado pelo atravessamento das plataformas virtuais e pelo desdobramento da tradicional interlocução diádica em uma tríade interativa composta por debatedores/as, a plateia e o aparato tecnológico. Em um universo tão eclético, é notória a profusão de eventos sobre temas do nosso campo de interesse, parentalidade, neste formato que parece ter vindo para ficar. Há uma expressiva e crescente variedade de eventos virtuais que reúne profissionais de diferentes áreas e mães que se colocaram a tarefa de orientar acerca dos desafios impostos pelas condições de isolamento ao pleno exercício da parentalidade e suas repercussões.

Como em variados momentos de crise, esta é também uma oportunidade de produção de novos olhares e reinvenção de práticas, e essas lives, que se oferecem como fontes de dicas e espaços de compartilhamento e troca de ideias, para além de possuírem uma função psicoeducativa, se atribuem ainda a tarefa de regulação da estabilidade emocional de pais e 


\section{Nanduty}

ISSN:2317-8590

mães e até mesmo dos/as filhos/as. Os conselhos e as assertivas sobre como ser pai e mãe integrais brotam em quantidade.

Ao que parece, as condições impostas pelo isolamento evocaram a necessidade de falar, bem como de aprender, sobre algo que até então parecia estar diluído na vivência do cotidiano de pais, mães e filhos/as. A banalidade do dia a dia, que está em tomar café da manhã, assistir aulas, tomar banho, almoçar, fazer atividades físicas, jantar, ver televisão se transforma em tema de interesse.

A parentalidade parece estar sendo (re)aprendida por pais que se julgavam experientes, e o conteúdo midiático online ganha uma expressiva importância neste processo. A internet tornou-se o meio de comunicação por excelência mais seguro e eficaz, e uma profusão de lives sobre assuntos diversos surgiram em resposta à demanda de entretenimento e de conhecimento acerca de como lidar com as especificidades da atualidade.

Nota-se que a ocupação do espaço virtual por especialistas e não especialistas para ensinar sobre o exercício da parentalidade surge como resposta a uma demanda, sobretudo de pais, aos desafios deste novo momento. Assim, aquilo que antes entendia-se aprender "naturalmente", na prática ou no convívio com as gerações anteriores, agora aprende-se online, em lives ou aulas virtuais. Tem sido na tela do computador que se está aprendendo e ensinando a viver fora dela.

Este artigo pretende analisar lives sobre parentalidade em tempos de pandemia, disponíveis no Youtube, considerando olhares sobre o exercício parental, a forma como a criança é vista neste mundo de intenso convívio familiar em que a vida dela é decidida por adultos/as e a preponderância da maternidade no exercício do cuidado.

\section{"VOCÊ NÃO SABE O QUANTO EU CAMINHEI, PRA CHEGAR ATÉ AQUI..." ": DESAFIOS METODOLÓGICOS EM TEMPOS DE PANDEMIA}

No contexto de isolamento social provocado pela situação de pandemia reconhecida pela Organização Mundial de Saúde (OMS) em março de 2020, frente ao embate de contágio do vírus COVID-19, que até o início do mês de agosto de 2021 é responsável pela morte de 4.265.903 $23^{2}$ pessoas ao redor do mundo, dentre elas $559.607^{3}$ óbitos no Brasil - entendendo que pode haver subnotificação - nos propomos a discutir a parentalidade, procurando entender o

\footnotetext{
${ }^{1}$ Trecho da letra da música A Estrada, do grupo Cidade Negra.

${ }^{2}$ Disponível em: https://covid19.who.int

${ }^{3}$ Disponível em: https://covid19.who.int/region/amro/country/br
} 


\section{Nanduty}

ISSN:2317-8590

que profissionais e famílias com crianças e adolescentes nessas interações vêm elaborando/construindo diante da atual realidade.

Para isso, optamos por analisar lives e alguns vídeos curtos nos quais essas discussões estivessem sendo colocadas, visto a profusão do uso desse recurso neste contexto em que os encontros presenciais estão ou deveriam estar proibidos ou sendo desencorajados pelo poder público. Dessa forma, concentramos a busca de material em uma única plataforma: o Youtube. Essa escolha se deu pelo fato de ali estarem concentrados vídeos feitos para o próprio Youtube, como também aqueles transmitidos em outras plataformas digitais, como o Facebook, Twitter e o Instagram e, facilitando a pesquisa, nesta plataforma é possível fazer uma busca por palavras-chave.

Parentalidade e pandemia foram as duas palavras-chave escolhidas e que cruzamos no mecanismo de busca do Youtube. Cada integrante do grupo anotou as 40 primeiras referências que apareceram do cruzamento dos dois termos, que somavam lives e vídeos em formatos diversos. Logo descobrimos que não necessariamente eram sobre o tema. Retiramos o que fugia completamente à temática ficando com 316 títulos e, no momento seguinte, de posse deste levantamento inicial individual realizado pelas 10 pessoas do grupo, cruzamos os títulos das lives e vídeos para descobrir quais se repetiam e com que frequência, determinando o conjunto a ser analisado. Com este procedimento, obtivemos uma lista com 26 vídeos, com uma variação de repetição entre 10 e 5 vezes, que foram distribuídos entre nós, usando como único critério um balanceamento das horas que os assistir demandaria. Cada vídeo foi visto por uma pessoa e cada live por duas. Nossa ideia era que assim seria possível levantar uma diversidade maior de aspectos a serem discutidos, com diferentes olhares e expectativas sobre o que seria apresentado. 


\begin{tabular}{|c|c|c|}
\hline NOME DO VÍDEO & PÁGINA/PERFIL & LINK \\
\hline $\begin{array}{l}\text { Live: Quais as novas } \\
\text { configurações que a } \\
\text { pandemia traz para } \\
\text { parentalidade e trabalho? }\end{array}$ & Humanos de negócios & $\begin{array}{l}\text { https://www.youtube.com/watch?v=6ttcq3y2j } \\
\text { OU }\end{array}$ \\
\hline $\begin{array}{l}\text { Lapsivi Discute: } \\
\text { Parentalidade e infância } \\
\text { em tempos de pandemia }\end{array}$ & $\begin{array}{l}\text { Lapsivi Laboratório de } \\
\text { psicanálise }\end{array}$ & $\begin{array}{l}\text { https://www.youtube.com/watch?v=11O36cz4 } \\
\text { 0GA }\end{array}$ \\
\hline $\begin{array}{l}\text { Live - A pandemia como } \\
\text { possibilidade de } \\
\text { reconexão entre escola x } \\
\text { família }\end{array}$ & $\begin{array}{l}\text { Amaná Educacional - } \\
\text { Regina Shudo }\end{array}$ & $\begin{array}{l}\text { https://www.youtube.com/watch?v=ym73N5q } \\
\text { kMuM }\end{array}$ \\
\hline $\begin{array}{l}\text { Aula Pública ADUFRGS } \\
\text { - Mulher, maternidade e } \\
\text { trabalho em tempos de } \\
\text { pandemia COVID-19 }\end{array}$ & Adufrgs & $\begin{array}{l}\text { https://www.youtube.com/watch?v=N7nKMc } \\
\text { EHJaM }\end{array}$ \\
\hline $\begin{array}{l}\text { Reflexões sobre a } \\
\text { primeira infância em } \\
\text { tempos de pandemia }\end{array}$ & Instituto Casa Grande & $\begin{array}{l}\text { https://www.youtube.com/watch?v=-dn- } \\
\text { WBdLoUY }\end{array}$ \\
\hline $\begin{array}{l}\text { Amor e Desamor na } \\
\text { Pandemia, com Vera } \\
\text { Iaconelli e Mario Vitor } \\
\text { Santos }\end{array}$ & Casa do saber & $\begin{array}{l}\text { https://www.youtube.com/watch?v=9nQATh } \\
\text { Z9q24\&ab_channel=CasadoSaber }\end{array}$ \\
\hline $\begin{array}{l}\text { Gestação, estresse e } \\
\text { pandemia: que tal uma } \\
\text { nova perspectiva? Por } \\
\text { Tiane Salum, obstetra } \\
\end{array}$ & Nasce saúde & $\begin{array}{l}\text { https://www.youtube.com/watch?v=N4x9cQjl } \\
\text { d9Y }\end{array}$ \\
\hline $\begin{array}{l}\text { Pandemia e ansiedade: } \\
\text { como acolher crianças }\end{array}$ & $\begin{array}{l}\text { Canal da ansiedade: } \\
\text { terapeuta Elsie Herber }\end{array}$ & $\begin{array}{l}\text { https://www.youtube.com/watch?v=f8dJaMp } \\
\text { Oom4 }\end{array}$ \\
\hline $\begin{array}{l}\text { Desafios para mulheres } \\
\text { da pandemia Covid-19: } \\
\text { reflexões no âmbito } \\
\text { universitário }\end{array}$ & Uniteve Uff & $\begin{array}{l}\text { https://www.youtube.com/watch?v=11kFWaD } \\
\text { UeOg }\end{array}$ \\
\hline $\begin{array}{l}\text { Webinar: Desafio } \\
\text { Universitário pela } \\
\text { Primeira Infância - } \\
\text { Fortalecimento da } \\
\text { Parentalidade } \\
\end{array}$ & ANUP Oficial & $\begin{array}{l}\text { https://www.youtube.com/watch?v=oRBwEm } \\
\text { LpyRc }\end{array}$ \\
\hline $\begin{array}{l}\text { Live Reinventar | } \\
\text { Parentalidade em } \\
\text { construção: ser família } \\
\text { em tempos de pandemia }\end{array}$ & $\begin{array}{l}\text { Reinventar integrando } \\
\text { seres e saberes }\end{array}$ & $\begin{array}{l}\text { https://www.youtube.com/watch?v=- } \\
\text { 59b2jQ11C4 }\end{array}$ \\
\hline $\begin{array}{l}\text { Pais e Filhos: Como } \\
\text { conviver nos tempos de } \\
\text { Pandemia, com Adriana } \\
\text { Friedmann e Mario Vitor } \\
\text { Santos }\end{array}$ & Casa do saber & $\begin{array}{l}\text { https://www.youtube.com/watch?v=AdSji7lm } \\
\text { Mas }\end{array}$ \\
\hline $\begin{array}{l}\text { Como educar xs filhxs em } \\
\text { tempo de pandemia e } \\
\text { pandemônio - com Vera } \\
\text { Iaconelli }\end{array}$ & $\begin{array}{l}\text { Inconsciente Coletivo } \\
\text { Entrevista }\end{array}$ & $\begin{array}{l}\text { https://www.youtube.com/watch?v=rnL- } \\
\text { FyQTQGI }\end{array}$ \\
\hline $\begin{array}{l}\text { EVENTO: Sobre bebês e } \\
\text { crianças em tempo de } \\
\text { pandemia. }\end{array}$ & $\begin{array}{l}\text { Clínica e Instituto } \\
\text { Horizontes }\end{array}$ & $\begin{array}{l}\text { https://www.youtube.com/watch?v=VOXTGj } \\
\text { vnyOQ }\end{array}$ \\
\hline
\end{tabular}




\begin{tabular}{|c|c|c|}
\hline $\begin{array}{l}\text { IERBB/MPRJ } \\
\text { CONECTA: Primeira } \\
\text { Infância em Tempos de } \\
\text { Pandemia }\end{array}$ & IERBB/MPRJ & https://www.youtube.com/watch?v=1 KEVJYS5V8g \\
\hline $\begin{array}{l}\text { HIPERCONVIVÊNCIA } \\
\text { em CASA | Maria } \\
\text { Homem }\end{array}$ & Canal Maria Homem & https://www.youtube.com/watch?v=YLNxbfMseXA \\
\hline $\begin{array}{l}\text { Desafios à parentalidade } \\
\text { em tempos de } \\
\text { coronavírus: Regras e } \\
\text { Rotinas. }\end{array}$ & $\begin{array}{l}\text { Comunidade } \\
\text { intermunicipal da Ave }\end{array}$ & $\begin{array}{l}\text { https://www.youtube.com/watch?v=14gygUcS } \\
\text { Lxk }\end{array}$ \\
\hline $\begin{array}{l}\text { SER MÃE E SER PAI } \\
\text { NA PANDEMIA } \\
\text { COVID-19 - } \\
\text { PARENTALIDADE } \\
\text { MINDFUL }\end{array}$ & AEC Vizela & $\begin{array}{l}\text { https://www.youtube.com/watch?v=0LzKQa8 } \\
\text { 3tZE }\end{array}$ \\
\hline $\begin{array}{l}\text { Desafios à parentalidade } \\
\text { em tempos de } \\
\text { coronavírus: Dicas de } \\
\text { apoio ao estudo em casa. }\end{array}$ & $\begin{array}{l}\text { Comunidade } \\
\text { intermunicipal da Ave }\end{array}$ & $\begin{array}{l}\text { https://www.youtube.com/watch?v=pFSbMk } \\
\text { WI-cw }\end{array}$ \\
\hline $\begin{array}{l}\text { Desafios à parentalidade } \\
\text { em tempos de } \\
\text { coronavírus: Brincar }\end{array}$ & $\begin{array}{l}\text { Comunidade } \\
\text { intermunicipal da Ave }\end{array}$ & https://www.youtube.com/watch?v=FYnUnOLx-cw \\
\hline $\begin{array}{l}\text { Desafios à parentalidade } \\
\text { em tempos de } \\
\text { coronavírus: Estratégias } \\
\text { para ajudar as crianças a } \\
\text { acalmar. }\end{array}$ & $\begin{array}{l}\text { Comunidade } \\
\text { intermunicipal da Ave }\end{array}$ & $\begin{array}{l}\text { https://www.youtube.com/watch?v=qA2pjyz8 } \\
\text { xtw }\end{array}$ \\
\hline $\begin{array}{l}\text { Desafios à parentalidade } \\
\text { em tempos de } \\
\text { coronavírus: Como } \\
\text { prevenir o burnout } \\
\text { parental? }\end{array}$ & $\begin{array}{l}\text { Comunidade } \\
\text { intermunicipal da Ave }\end{array}$ & $\begin{array}{l}\text { https://www.youtube.com/watch?v=EeqyaU9 } \\
\text { L3xU }\end{array}$ \\
\hline $\begin{array}{l}\text { Desafios à parentalidade } \\
\text { em tempos de pandemia: } \\
\text { Comunicação positiva e } \\
\text { mensagens na primeira } \\
\text { pessoa }\end{array}$ & $\begin{array}{l}\text { Comunidade } \\
\text { intermunicipal da Ave }\end{array}$ & $\begin{array}{l}\text { https://www.youtube.com/watch?v=Vyw1Al } \\
\text { UYZq8 }\end{array}$ \\
\hline $\begin{array}{l}\text { Impactos da Pandemia } \\
\text { nos Filhos e Pais }\end{array}$ & Paizinho Vírgula & https://www.youtube.com/watch?v=jwVeWrTEgCc \\
\hline $\begin{array}{l}\text { Parentalidade e } \\
\text { Quarentena }\end{array}$ & $\begin{array}{l}\text { Li educa - ligiane } \\
\text { gomes }\end{array}$ & https://www.youtube.com/watch?v=tdDN34v1AJ4 \\
\hline $\begin{array}{l}\text { Durante a quarentena } \\
\text { provocada pelo } \\
\text { coronavírus, como fica o } \\
\text { direito de visita? }\end{array}$ & $\begin{array}{l}\text { Franco Mazieiro - } \\
\text { Canal Mais Direito }\end{array}$ & $\begin{array}{l}\text { https://www.youtube.com/watch?v=38Nu9TRMlu8\&t } \\
=7 \mathrm{~s}\end{array}$ \\
\hline
\end{tabular}

Figura 1 (Autores) 


\section{Nanduty}

ISSN:2317-8590

É preciso destacar que o resultado da pesquisa de cada pessoa do grupo foi certamente marcado pelos sites que visita, vídeos que costuma assistir no Youtube. Sabemos que os algoritmos estão no comando, as indicações que aparecem não são aleatórias e não temos nenhuma ingerência sobre elas. Silva \& Grillo (2019) chamam a atenção para a necessidade de adaptação de conteúdos de divulgação científica para o meio digital e, neste sentido, o Youtube agora é grande propagador de conhecimento. Por mais que haja alguma interação simultânea, ela é feita com recursos diferentes: alguém fala e alguém escreve, com os tempos de cada uma dessas habilidades humanas. Ressalta-se ainda o fato de o material ser eternalizado, podendo ser acessado a qualquer tempo. O risco? Cristalizar naquele momento da live as formas de pensar das pessoas envolvidas.

A tela mostra nossas casas em 2D e é possível, quase sempre, escolher o que mostrar e o que esconder. Em algumas das lives, as crianças adentram o cômodo de onde fala a mãeprofissional-palestrante, dando mais legitimidade àquela fala sobre parentalidade. Em algumas dessas lives, a internet da palestrante caiu. Como lidar com essas interrupções? Outro desafio colocado por esta vida majoritariamente digital.

Dentre os vídeos selecionados, em apenas dois o expositor é um homem. Todas as pessoas são brancas, das regiões sul e sudeste do Brasil, e é possível imaginar que sejam das camadas médias da população em função da forma como abordavam as questões, dos pressupostos de bens e serviços que entoavam acreditar haver entre as pessoas que assistiam as lives e dos cenários que a tela do computador nos mostrava. As palestras foram feitas em sua maioria por psicólogas e pedagogas, mas aparecem também professora, mãe, pai, enfermeira, ginecologistaobstetra e uma arquiteta. O público a que se dirigem é basicamente de pais e mães, sendo apenas duas voltadas para estudantes de psicologia. Há uma certa normatividade nas falas, um pressuposto forte de que o universo para o qual se dirigem sejam famílias nas quais há paishomens-cis, mães-mulheres-cis e filhos/as, gerados pela relação sexual entre pai e mãe, mesmo que sejam divorciados.

Os vídeos curtos são pequenas lições sobre como regular emoções em tempos de pandemia, visando uma relação entendida como saudável entre pais, mães, filhos e filhas. Burnout parental, mindfulness, diferenças entre distanciamento físico e distanciamento social são alguns dos temas tratados por uma psicóloga portuguesa que produz uma série de seis vídeos, tendo quatro aparecido em nossos cruzamentos. 


\section{Nanduty}

ISSN:2317-8590

Nas lives analisadas, a pandemia aparece como algo a ser simbolizado (Live Sobre bebês e crianças em tempo de pandemia) como momento de exaustão (Live Como educar xs filhxs em tempo de pandemia e pandemônio e Desafios à parentalidade em tempos de pandemia: Comunicação positiva e mensagens na primeira pessoa) e medo (Live Desafio Universitário pela Primeira Infância - Fortalecimento da Parentalidade), mas também como oportunidade de transformação (Live Reinventar - Parentalidade em construção: ser família em tempos de pandemia).

$\mathrm{Na}$ proposta do texto, dois processos novos se colocam como desafio: escrever e transmitir na pandemia. Nosso trabalho de pesquisadoras e pesquisadores em diferentes níveis de formação é atravessado com intensidade pela pandemia que obrigou a transformar os planos iniciais de muitas pesquisas, acabou com os encontros presenciais dos grupos de pesquisa cujos afetos se habituaram ao mundo $3 \mathrm{D}$, mas propicia uma escrita respeitosa e conjunta através do drive e de discussões no Zoom.

\section{NOS EXERCÍCIOS DA PARENTALIDADE}

Durante muitos anos, o termo paternidade tanto se referiu ao homem, quanto ao exercício parental de pais e mães. Não apenas pela ausência de um termo mais adequado, mas sobretudo pela autoridade que o pai detinha na família, fosse social ou juridicamente, até a Constituição Federal de 1988, que garante a igualdade entre homens e mulheres. Segundo Dantas et al (2019), o termo parentalidade tem sido adotado desde a década de 1980 para tratar de aspectos conscientes e inconscientes do exercício parental. Ao falar em parentalidade, remete-se aquele e/ou àquela que exerce esta função de cuidado, no singular ou no plural, independentemente do gênero, colocando o/a outro/a no lugar de filho/a.

Como veremos, uma série de nomes, conceitos e neologismos aparecem na tentativa de nomear, conter ou mesmo controlar a natureza imprevisível e inédita da atualidade. Os títulos dos vídeos e das lives, bem como os termos utilizados ao longo das explanações, denotam a necessidade de nomear uma situação sem precedentes no nosso século, e para qual o repertório de palavras é escasso para refletir a maneira como sentimos e lidamos com o clima emocional de um momento desconhecido: a integralidade temporal e espacial da parentalidade. Termos como "hiperconvivência", "parentalidade integral", "parentalidade pandêmica", dentre outros, possuem em comum a nomeação de algo que parece intenso, excessivo, circunstancial ou ainda que transborda os limites daquilo que se era ou se tinha anteriormente. 


\section{Nanduty}

ISSN:2317-8590

Faz-se necessário destacar que a parentalidade concebe o cuidado parental que inclui aspectos físicos, emocionais e sociais que visam o desenvolvimento da prole. Espera-se dos pais e das mães - ou ainda familiares que exercem esta função - que propiciem segurança e autonomia para os/as filhos/as, a fim de desenvolver a capacidade de tomar decisões e viver no coletivo. Para autores e autoras que trabalham com esta terminologia, a parentalidade positiva - também tratada na live "Quais as novas configurações que a pandemia traz para parentalidade e trabalho?" - promove o cuidado físico (alimentação, higiene, vestuário para proteger), emocional (comportamento parental para promover apego, segurança e autonomia para tomadas de decisão) e social (estimulação das relações interpessoais ampliadas) (Barroso \& Machado, 2015; Linhares, 2015).

No contexto de pandemia e isolamento físico, o virtual e o real passaram a se sobrepor, a se confundir, a se compor numa troca intensa de experiências e aprendizados. Segundo Bronfenbrenner (2011), eventos ocorridos ao longo da história podem afetar o desenvolvimento humano de forma positiva ou negativa, tanto do ponto de vista individual quanto populacional. No momento atual, em 2020/2021, a população mundial está enfrentando uma experiência adversa devido à grave ameaça à sobrevivência provocada pela pandemia da COVID-19, que vem testando a capacidade de nos relacionarmos, de convivermos e até mesmo de nos distanciarmos. Nos faz enfrentar uma nova equação: distanciamento e ausência de contato físico geram cuidado e proteção. Na contramão do que fomos educados/as.

Podemos perceber que esse evento de contaminação em larga escala, com perspectivas lentas de medidas farmacológicas efetivas para deter essa epidemia ${ }^{4}$, tem provocado um contexto altamente estressor, que se reflete sobremaneira no sistema familiar (Liang, 2020) e no desenvolvimento de idosos/as, adultos/as, crianças e adolescentes.

As fronteiras entre estes dois mundos (real e virtual) nunca estiveram tão borradas, porosas e permeáveis entre si. Com isso, os/as autonomeados/as influencers tornaram-se uma potência sem precedentes na curta história da internet (Rosa, Santos \& Faleiros, 2016). Notase um movimento inédito de pais afirmando reaprender a parentalizar seus/suas filhos/as, a partir de lives ministradas geralmente por especialistas que compartilham seus conhecimentos e trocas pessoais no movimento coletivo de "mostrar o que se sabe" acerca dos desafios da "parentalidade pandêmica", expressões recorrentes nas lives analisadas.

\footnotetext{
${ }^{4}$ Importante lembrar que no período da escritura deste texto o Brasil ainda não tinha dado início à vacinação.
} 


\section{Nanduty}

ISSN:2317-8590

A entrada do campo profissional no espaço doméstico é verificada também na fala dos/as referidos/as especialistas, que eventualmente oferecem relatos de suas histórias pessoais para ilustrar aquilo que estão teorizando. Esta mescla do pessoal e do profissional responde ao desejo de exemplificar uma fala especializada, buscando uma legitimidade que se constrói também a partir da vivência.

Apesar dos temas serem abordados de diversos pontos de vista científicos e não científicos há uma preponderância da discussão da parentalidade a partir do lugar ocupado pelas mulheres nas configurações familiares, em especial da maternidade.

Como vimos na live "Parentalidade e infância em tempos de pandemia", a entrevistada atrasa-se alguns minutos para o evento em função do início das aulas online de seu filho, e aproveita o ensejo para elucidar o tema sobre o qual irá debater, comentando que se trata "da parentalidade na insanidade da experiência online" ${ }^{5}$. Também em "Gestação, estresse e pandemia: que tal uma nova perspectiva?", observamos a presença de crianças no início das transmissões, revelando ao público esse lugar para além da mera informação verbal. A aparição em princípio inesperada dos/as filhos/as nas lives legitima este lugar da especialista e mostra ao vivo e em cores o que está sendo debatido.

Em outro vídeo, a psicanalista Vera Iaconelli (2020) demonstra como a sua dinâmica familiar mudou em função do confinamento com as filhas adolescentes. Neste caso, a vida pessoal e a vida profissional disputam e se cruzam, inaugurando uma fala especializada com um relato íntimo e vivencial a respeito da "parentalidade em tempos de pandemia".

Por outro lado, em "Paizinho Vírgula", um pai usa de sua experiência pessoal para justificar a especialidade do conteúdo apresentado em seus vídeos. Nessas fronteiras borradas, ou nas novas exigências deste tipo de comunicação, pais e mães autonomeiam-se especialistas, difundindo seu conhecimento cotidiano, e especialistas usam suas experiências como pais e mães na árdua tarefa de imprimir singularidade às suas falas neste momento.

Já em "Pandemia ou pandemônio" o humor serve de ferramenta para exprimir a intensidade dos desafios oriundos da parentalização em tempo integral, e faz menção ao caos cotidiano que permeia a vida dos/as pais/mães/autores/as deste vídeo.

Interessante apontar que nesta dinâmica do dito e do não dito pela transmissão do vídeo nota-se o desenvolvimento de uma ferramenta comunicativa - a pessoalidade. Anderson (2016) escreve como se dá o sucesso das palestras TED Talks na plataforma Youtube: "sua primeira

\footnotetext{
${ }^{5}$ Fala transcrita da live. Usaremos aspas quando tivermos transcrito a fala de alguma pessoa nas lives.
} 


\section{Nanduty}

ISSN:2317-8590

tarefa como palestrante é encontrar a maneira de (...) construir um laço humano de confiança com seus ouvintes para que eles se disponham a lhe dar pleno acesso a suas mentes durante alguns minutos" (Anderson, 2016: 55). Do mesmo modo, afirma que a narração a partir de histórias pessoais são as que garantiram as palestras de maior acesso e sucesso da plataforma e que "é natural que, ao escutar uma história, o ouvinte mostre empatia com as experiências vividas pelos personagens. Ele se vê imerso em seus pensamentos e emoções." (Anderson, 2016: 69). E parentalidade é certamente uma temática propícia.

Dentro desse campo, o especialismo da comunicação por meios digitais se soma às camadas, de maneira planejada ou não, do lugar científico e da maternidade. Esse afetar das experiências narradas perpassadas na construção de um saber que mescla o científico e a pessoalidade de um modo que o afetar "denuncia que algo está acontecendo, e que nosso saber é mínimo nesse acontecer. Sinaliza a força de expansão da vida e da vida que podemos viver. A tensão se instala" (Fonseca, Nascimento \& Maraschin, 2012: 26).

Deste modo, o lugar do especialista, aquele/a que detém o conhecimento científico, autoriza o lugar da fala, mas é a experiência pessoal que legitima a narrativa e medeia os afetos vividos nesse momento de pandemia.

$\mathrm{Na}$ base dos desafios e das questões supracitadas encontra-se um termo apresentado em um dos vídeos analisados: a hiperconvivência. Ao abordar o presente momento, a psicanalista Maria Homem (2020) recorre a este neologismo para nomear o fenômeno do confinamento "com o outro e consigo" durante a pandemia. Segundo a autora, trata-se de "uma palavra que está circulando e que pode ajudar a pensar em como é viver no atual momento" (HOMEM, 2020:25). Destaca-se, ainda, o caráter existencial da crise, vista no vídeo em questão como "uma oportunidade de ouro nas mãos" para estabelecer uma conexão mais legítima consigo e com os outros. Segundo Homem (2020), a hiperconvivência nos obriga a ocupar a cena metafórica do "Anjo exterminador", fazendo menção ao filme homônimo no qual um jantar desdobra-se em um "experimento sócio psíquico” que obriga os convidados a permanecerem no evento.

$\mathrm{Na}$ hiperconvivência, tal como no filme, os até então conhecidos revelam-se desconhecidos, e pode-se perceber as pequenas facetas, gestos e reações do outro que geram admiração ou repulsa. Na parentalidade, a questão da hiperconvivência torna-se familiar, e os familiares, neste sentido, desconhecidos em potencial. Será? 


\section{Nanduty}

ISSN:2317-8590

Outras lives, como "Parentalidade e pandemia", destacaram a oportunidade de uma real aproximação e da autorrevelação possível entre os integrantes de um mesmo grupo familiar, inclusive entre pais/mães e filhos/as. O aumento do convívio familiar de fato pode propiciar um conhecimento mais denso deste/a filho/a. Tem-se um consenso de que o tempo excessivo de quarentena demanda uma adaptação que tem sido chamada de "nova normalidade" por algumas pessoas, e com isso surgem novas dinâmicas e novas regras como estratégias de convívio familiar (Guizzo, Marcello \& Muller, 2020).

Sobre este ponto, ganha destaque a fala recorrente de alguns pais e algumas mães, "quero mandar logo meu/minha filho/a para a escola”, e a necessidade pontuada pelas autoras (Guizzo, Marcello \& Muller, 2020) de refletir sobre que filho/a é esse que está sendo mandado de volta para a escola. Para as autoras, subjacente ao discurso mencionado, há um mecanismo defensivo de resistência ao processo de conhecer o/a filho/a tal como ele/a se apresenta, e frustrar-se em relação ao/à filho/a idealizado/a. Destaca, ainda, a implicação ética dos/as pais/mães de conhecerem o/a filho/a que é enviado/a para a escola, tendo em vista que "este é um/a adulto/a em formação para o mundo futuro”. Além disso, as autoras destacam como as crianças, e não somente os/as pais/mães, sofrem com o atual momento de pandemia. Por exemplo, é abordada a questão da "criança invisível", que se refere ao fato de que embora as crianças não adoeçam, é necessário que fiquem em casa e não podem ir à escola, pois podem ser transmissoras do coronavírus. Apesar de serem supostamente imunes ao vírus, as crianças são suscetíveis às questões emocionais decorrentes da atual configuração pandêmica (Linhares \& Enumo, 2020). Um perigo potencial e invisível. Neste sentido, faz-se urgente uma abordagem inclusiva de todos os espectros etários presentes na família para um enfrentamento adequado destes desafios.

Ainda sobre a necessidade premente de se mandar filhos e filhas para a escola, é também possível pensar que mães e pais não se sentem aptas e aptos e/ou não estão disponíveis para esta parte da educação que é de competência da escola. Pode significar também o reconhecimento daquele espaço como fundamental para a formação de crianças e adolescentes. É necessário buscar múltiplos olhares sobre os novos fenômenos. Se a hiperconvivência pode nos fazer perceber aspectos de nossas vidas sobre os quais nunca pensamos, também nos faz perceber a importância e a especificidade dos diversos espaços que frequentamos e que estão tão naturalizados que sequer pensamos sobre eles, como a escola e o trabalho.

Outra reflexão importante a se fazer é sobre a maneira de abordar a pandemia com os filhos e filhas, destacando que falar abertamente sobre o atual momento ou inventar uma 


\section{Nanduty}

ISSN:2317-8590

história são extremos de uma gama de possibilidades, visto que sempre se apresenta uma forma diferente de abordar essa temática e nenhuma delas pode ser considerada totalmente certa ou errada (Linhares \& Enumo, 2020).

Percebe-se que o novo coronavírus trouxe mudanças expressivas para o convívio familiar e principalmente no que se refere às relações entre as figuras parentais. A pandemia propiciou uma aproximação com os equipamentos tecnológicos de forma mais intensa, fez com que acontecesse um afastamento do convívio com pessoas fora de casa e acabou por intensificar o convívio de familiares que se viram presos em suas casas. Diante de tantas demandas parentais abordadas nas lives, percebe-se que houve uma necessidade de conversar, discutir, debater e apresentar esse novo modelo de se relacionar fora e dentro de casa. Fora pela vida da tecnologia e redes sociais, dentro pela vida da convivência intensificada, constante e, por que não, por vezes, conflituosa.

Para Maria Homem (2020), o "fio da parentalidade" encontra-se exposto, uma vez que a hiperconvivência obriga todos os integrantes da trama familiar a reverem suas posições práticas e subjetivas na família. Não obstante, como verificado nas lives de Vera Iaconelli (2020), tratase de um período potencialmente revelador das facetas, até então ocultas, de um "outro familiar". É recorrente a noção de um suposto estranhamento em relação ao "outro familiar", e a possibilidade, por exemplo, de um "filho até então desconhecido" (HOMEM, 2020). De fato, a suspensão dos serviços de terceirização do cuidado (babás, escolas, dentre outros) impõe a pais, mães e filhos/as um convívio sem precedentes na história das famílias.

A literatura sobre o tema vem apresentando como a hiperconvivencia impõe a necessidade de negociação entre os ideais de cada familiar para com o/a outro/a, e com um suposto choque de realidade, imposto pelo convívio exacerbado e pelo estreitamento das relações familiares. Tais afirmações, no entanto, fundam-se, segundo Maria Homem (2020), nas lives sobre hiperconvivência que acrescentamos ao nosso grupo, no suposto desconhecimento parcial deste "outro familiar", e na premissa de que é durante o isolamento que "as máscaras" irão cair. São máscaras que vão cair ou novas máscaras que vão aparecendo, convidando aqui a forma como Suely Rolnik (1989) as entende. Diz a autora que "a máscara funciona como condutor de afeto (...) ganha espessura de real, ela é viva e, por isso, tem credibilidade: é verdadeira" (Rolnik, 1989: 31). Neste sentido, as máscaras não escondem algo que estava ali e não era visto, são posições que vamos ocupando no mundo. Não há uma essência por trás das máscaras, tudo o que somos são máscaras, que se constroem e se adaptam 


\section{Nanduty}

ISSN:2317-8590

ao que vamos vivendo. Algumas tornam-se obsoletas e deixam de existir. Surgem outras. O momento de pandemia exige novas máscaras, construídas com dúvidas, desejos, intensidades.

As atividades extra domésticas desempenhavam um papel preponderante na dinâmica das relações e na regência dos conflitos familiares, o que escancara a necessidade da intermitência das relações, pouco falada até este momento. Este cenário sugere que ainda é um tabu assumir a dificuldade de se conviver 24 horas por dia com quem em princípio se ama.

Em determinadas lives, o convite a falar sobre a parentalidade exercida por famílias socialmente vulnerabilizadas (com baixo poder aquisitivo, vítimas de algum tipo de opressão social) ou mesmo tematizar o racismo entranhado em nossa sociedade causou nos entrevistados profunda estranheza e desconforto. Como que pegos de sobressalto, vimos profissionais até então bastante seguros em suas explanações titubearem após serem questionados sobre os atravessamentos na parentalidade de questões como: preconceito racial, pobreza extrema e outros temas relacionados à desigualdade social. A interseccionalidade parecia não habitar suas análises.

E as crianças? Se são tão centrais, de que formas aparecem?

\section{FALA-SE DA CRIANÇA, MAS NÃO COM A CRIANÇA: MAIS UMA FORMA DE INVISIBILIDADE?}

Ainda que a figura da criança seja mencionada na maioria das lives assistidas por nós, para a produção deste trabalho, notamos que é sobre a criança que se fala, e não com a criança que também vivencia as questões colocadas pelo contexto pandêmico.

Mesmo que falar sobre a criança e não com a criança não seja um fenômeno novo, tampouco ocasionado pelo coronavírus ou efeito dos dispositivos digitais, gostaríamos de trazer algumas reflexões sobre a importância do envolvimento das crianças nos processos de gestão e deliberação das próprias vidas, nos diversos âmbitos que competem a sua existência.

Já há muito tempo nos espaços educacionais, nos domínios familiares ou em nossas próprias pesquisas acadêmicas a criança é posicionada vários degraus abaixo do adulto, raras vezes autônoma em seu próprio discurso ou presença. Raríssimas vezes encarnada em espaços nos quais o adulto conta histórias sobre ela ou apresenta resultados sobre os seus achados advindos de observações científicas (ou não): a criança segue subjacente, improvável.

Esse cenário que compreende a criança como um adulto em formação, ou circunscrita em um domínio inferior a ele, ainda em estado de alcançá-lo, para atingir, de fato, um pretenso 


\section{Nanduty}

ISSN:2317-8590

lugar no futuro, faz parte de uma lógica de operar no mundo, conhecida como adultocêntrica e que organiza o nosso modo de conviver com as crianças.

Dentro dos estudos da infância, Fúlvia Rosemberg (1976) foi uma das pioneiras ao tratar do termo adultocentrismo e problematizá-lo, como descrevem Campos et al (2014) em homenagem à professora e pesquisadora após o seu falecimento. De acordo com Rosemberg (1976), advinda de uma relação unívoca, a sociedade-centrada-no-adulto é construída para e por ele, tornando-o o emissor do conhecimento, enquanto pretende-se que a criança ocupe o papel de receptáculo, submissa no processo de aprender.

Ainda que seja um trabalho produzido no final da década de 70, assusta a propriedade das questões de Rosemberg (1976:1466) nos tempos atuais, principalmente quando a autora descreve que é "na dependência biológica da criança" compreendida como pequena, frágil ou inacabada que se embasa o poder dotado ao adulto.

Nesse cenário, a pesquisadora já estava alerta para a impossibilidade de a biologia dar conta de explicar todos os fenômenos que abarcam o desenvolvimento infantil. Mais do que isso, fica entendido que Rosemberg (1976) guardava ressalvas sobre o contexto de fragilidade atribuído às crianças a partir de uma leitura biológica do desenvolvimento, leitura que servia para embasar e naturalizar práticas de dominação adultocêntrica.

Quando assistimos as lives "Reflexões sobre a primeira infância em tempos de pandemia" com a palestrante Pollyana Fernandes Gomes, ou o webinar: "Desafio Universitário pela Primeira Infância - Fortalecimento da Parentalidade", com a professora Anna Chiesa, cujo foco é a primeira infância (0 a 6 anos), os estudos de Rosemberg (1976) ajudam a pensar os tempos atuais e nos (des)acomodam diante das perspectivas abordadas.

Fica explícito, nas lives, como a entrada da neurociência no campo da primeira infância e da educação infantil ganhou destaque como "evidência científica", retomando ideias biologicistas para explicar fenômenos multifacetados. Assim, a repetição e a centralidade da neurociência como aporte teórico-metodológico nos chamam a atenção e nos faz ficar às voltas com o que Rosemberg (1976) já sinalizava: o perigo da biologização da vida da criança, que passa a ser compreendida como "um vir a ser", que nunca é, no presente, deixando de existir no agora. Não no sentido do devir deleuziano, mas tornando-se parte de uma promessa futura.

As discussões propostas nas lives são bem diretivas nesse sentido: há muito o que se ocupar e preocupar com o neurodesenvolvimento infantil, pois é ele que vai formar as conexões cerebrais em uma velocidade importante, e que periga nunca mais acontecer. De acordo com 


\section{Nanduty}

ISSN:2317-8590

Chiesa, nos primeiros anos de vida "a gente tem a possibilidade de criar estruturas pra formar uma base que vai ser apoio pra todo o restante que acontece" ao passo que o papel da família ganha uma certa notoriedade, já que investindo em uma interação positiva com a criança "ela vai poder ... é ... ela vai ter um sucesso na escola, empregabilidade maior ... é ... controle emocional". Como se fossem decisões pessoais, individuais, sem análise do contexto social, tão desigual na sociedade brasileira.

No mesmo fio de pensamento, a palestrante Pollyana Fernandes Gomes adverte que "a primeira infância, ela é a arquitetura do cérebro, então a gente está montando aquela arquitetura inicial". Fica sinalizado que para a palestrante são os/as adultos/as que constroem as crianças e, a partir da estimulação neuropsicológica adequada, são eles/elas que vão proporcionar para elas o "palco para a vida, então ... é ... elas vão ser apresentadas a esse palco da vida e elas vão ter, elas vão ser protagonistas desse palco, desse cenário que você está apresentando a elas”. Ainda que sujeito em desenvolvimento, como preconizado pelo Estatuto da Criança e do Adolescente (ECA), a criança tem autonomia. Será que dizer que são protagonistas significa conceber sua autonomia? E como lembram Castro \& Grisolia (2016: 975), estão em "posição de simetria em relação ao adulto em termos de dignidade e humanidade".

Se o foco no neurodesenvolvimento decorre da preocupação em garantir um futuro próspero para os/as adultos/as, esse futuro só pode acontecer quando articulado ao mercado neoliberal. Em uma das lives, intitulada "IERBB/MPRJ CONECTA: Primeira Infância em Tempos de Pandemia", ministrada por duas Promotoras de Justiça, também professoras, além do reforço da importância das conexões neurais para o desempenho da criança, há também a defesa de que se deve olhar para a primeira infância a partir da lógica do capital humano, como garantia conjunta de um resultado satisfatório.

Em um momento da live, as promotoras conversam apontando que as infrações na adolescência podem ser fruto da experiência de uma primeira infância inadequada (como nomeiam), com a existência de maus-tratos, negligência etc. Seguem a conversa tratando do conceito de estresse tóxico, quando o prolongamento de situações estressantes compromete o desenvolvimento de circuitos neuronais, causando danos, riscos de doenças etc., como as próprias expositoras conceituam. Uma perspectiva que trata de forma bastante individualizante um fenômeno que é social. As afirmações da live, neste aspecto, fazem pensar na comum associação direta entre famílias pobres e delinquência, que deve ser analisada considerando a necropolítica (Mbembe, 2018) que constitui a sociedade brasileira. 


\section{Nanduty}

ISSN:2317-8590

Apesar da correlação do "estresse tóxico" com a neurologia, chama a atenção como as palestrantes sugerem que as camadas populares vulnerabilizadas são as mais propensas a essas situações. Uma das promotoras, ao trazer informações que denotam possíveis "déficits" no desenvolvimento infantil, aponta que "esses dados, essas informações sobre a primeira infância, são para as pessoas de alta vulnerabilidade".

O mesmo ocorre com o Manual de Orientação (Sociedade Brasileira de Pediatria, 2017), quando descreve que há uma relação estabelecida entre a pobreza e o desempenho intelectual na infância, estando o neurodesenvolvimento afetado por problemas ambientais. Chamam a atenção os efeitos deste tipo de afirmação. Estas falas denunciam um processo de criminalização da pobreza (Bonalume \& Jacinto, 2019), quando as famílias pobres, vulnerabilizadas, são culpabilizadas e tomadas pelos especialistas como incompetentes na criação dos/as filhos/as. Tal compreensão reduz e individualiza problemas de ordem social, principalmente vinculados aos efeitos do capitalismo neoliberal e da privação de direitos, conforme apontam as pesquisadoras Maria Lívia do Nascimento, Fabiana Lopes da Cunha \& Laila Maria Domith Vicente (2008).

Usando o economista James Heckman, pesquisador e vencedor do Prêmio Nobel de economia, as promotoras seguem com a ideia de que a infância, principalmente a infância pobre e vulnerabilizada, precisa ser lida como um investimento, para evitar riscos e problemas futuros. O pesquisador Rodrigo Saballa de Carvalho (2016), usando os conceitos de governamentalidade e capital humano do filósofo Michel Foucault (1926-1984), busca questionar o modo como as crianças vêm sendo tratadas por economistas, ocasionando como efeito o desenvolvimento de Políticas de Educação Infantil pautadas em intervenções precoces, principalmente com foco em famílias pobres, como evidenciamos. Nessa lógica, tais famílias lidas como deficitárias devem ser qualificadas, investidas, para tornarem-se produtivas e adaptadas ao trabalho e à formação de mão de obra. Se conseguirem escapar do fracasso já traçado como destino.

Foucault (2008) compreende o conceito de governamentalidade como a transformação do Estado em Estado de administração, junto do conjunto de instituições, procedimentos, análises, reflexões, cálculos e táticas que permitem o exercício do poder do governo sobre os outros poderes sociais, enquanto o conceito de capital humano se refere ao valor econômico de um trabalhador, envolvendo fatores como habilidades, inteligência, treinamento e educação, de forma que a capacidade de um indivíduo de se mostrar produtivo e lucrativo é valorizada. Esta 


\section{Nanduty}

ISSN:2317-8590

visão está diretamente relacionada à visão da infância e à modelação dos processos de ensino e aprendizagem atuais.

Esta perspectiva reforça a ideia da criança frágil, com capacidade neurológica melhor investida nos primeiros anos de vida, torna consistente as práticas de invisibilização do que a criança é no presente, do conhecimento que ela possui, dos trajetos que ela escolhe construir. E mesmo dos processos sociais em que está imersa.

Por outro lado, os novos contextos tecnológicos podem desempenhar uma mudança de perspectiva dessa realidade que subvaloriza as crianças, pois ajudam a borrar as hierarquias de saberes quando as crianças concretamente demonstram mais habilidades e conhecimento que os adultos, que precisam recorrer a elas para manejar todo o aparato informático.

Com a pandemia, ainda que se permaneça centrada no adulto, com todas as lives, vídeos e materiais informativos com orientações de como organizar a vida das crianças, cuidar delas, inseri-las em uma rotina, vez ou outra uma criança aparece correndo atrás da videoconferência de trabalho do pai ou da mãe, ou decide atrasar o início de alguma produção sobre parentalidade, tornando visível não só a si mesma, como uma série de questões que envolvem a sua participação na vida dos/as adultos/as e de como funcionamos como adultos/as no ocidente.

\section{"TODO DIA ELA FAZ TUDO SEMPRE IGUAL, ME SACODE ÀS SEIS HORAS DA MANH $\tilde{A}^{6} . . . ":$ MATERNIDADE EM TEMPOS DE PANDEMIA}

Evidências apontam que o Coronavírus/COVID-19 chegou ao Brasil, via ponte aérea, provindo de algum país europeu. Porém, foi num leito do Sistema Único de Saúde - SUS - em Miguel Pereira, cidade do interior, que o vírus fez sua primeira vítima fatal do Estado do Rio de Janeiro. A mulher de 63 anos, apesar de ter como endereço fixo a casa na qual moram seus familiares, na cidade supracitada, passava a maior parte da semana na casa onde exercia seu trabalho há mais de dez anos, no Leblon, bairro nobre da Zona Sul da cidade. Na ocasião de seu adoecimento, sua patroa - como até hoje falamos - havia chegado poucos dias antes de uma viagem a Itália e aguardava pelo resultado do exame para COVID- 19, que posteriormente foi noticiado como positivo. A patroa contactou a família de sua funcionária alegando a necessidade de buscarem-na para receber os cuidados de saúde em seu município de origem, após a mesma passar mal. A senhora veio a óbito no dia seguinte, em 17 de março de 2020, no Hospital Municipal Luiz Gonzaga em Miguel Pereira, antes mesmo de saber o resultado de seu

\footnotetext{
${ }^{6}$ Trecho da música Cotidiano, de Chico Buarque.
} 


\section{Nanduty}

exame. Familiares relataram sentimentos de tristeza, medo e revolta, avaliando que o isolamento social da dona da casa poderia ter poupado a vida dessa senhora.

Além de outros atravessamentos é nítido, neste trágico episódio, a invisibilização deste trabalho e de quem o exerce. A vida restrita ao lar, imposta pela necessidade de isolamento social, descortinou por quem esse trabalho é exercido e o quanto custa manter tarefas que pareciam, anteriormente, escondidas nos bastidores - nunca para quem os exerce.

O premiado longa metragem Roma (2018), de direção de Alfonso Cuarón, retrata a vida de Cléo, no início dos anos 1970, interpretada por Yalitza Aparício, no México. Cleo, assim como a mulher que trabalhava no Leblon, também dedicava sua vida a uma família rica, cuidava dos quatro filhos de Sofia e de todas as outras tarefas que envolvem a manutenção da rotina de uma casa. No início da trama, a funcionária tem momentos pessoais em seus dias de folga - vai ao cinema e conhece pessoas, por exemplo, mas, ao longo do filme, suas vivências são cada vez mais conciliáveis com a vida da família empregadora. A rotina e a previsibilidade do dia a dia de Cleo são retratados no filme em preto e branco, o que parece destacar o prenúncio do destino dela. Cuarón descreve o longa como autobiográfico evidenciando o protagonismo e afeto que podem ocupar as pessoas adultas que cuidam das crianças.

Regina Casé, ao dar vida a Val, protagonizou o, também premiado, Que horas ela volta? (2015). A pernambucana se muda para São Paulo visando enviar dinheiro para promover melhores condições de vida a sua família, incluindo sua filha, Jéssica, interpretada por Camila Márdila. O longa evidencia situações de preconceito e exploração, além de trazer análises acerca de possibilidades de resistência ao quadro e reinvenção da vida. Val, ao se dedicar aos cuidados da família paulistana e Fabinho, filho do casal empregador, que tem a mesma idade de Jéssica, não reconhece mais a filha e nem sabe que é avó, porém, o reencontro a potencializa.

Desde o surgimento do capitalismo na Europa, homens e mulheres passaram a ser vistos sob a lógica de produção e consumo. Trabalhos relacionados à manutenção da casa, bem como toda a responsabilidade na criação de crianças, foram designados às mulheres, ao passo que trabalhos externos, ligados à produtividade e ao capital, couberam aos homens, havendo uma divisão sexual do trabalho. A existência de homens era reduzida ao trabalho, enquanto a das mulheres era gerar e criar novos trabalhadores.

A divisão sexual do trabalho que emergiu daí não apenas sujeitou as mulheres ao trabalho reprodutivo, mas também aumentou sua dependência, permitindo que o Estado e os empregadores usassem o salário masculino como instrumento para comandar o trabalho das mulheres. Dessa forma, a separação efetuada entre a produção de mercadorias e a reprodução da força de trabalho também tornou possível o 
desenvolvimento de um uso especificamente capitalista do salário e dos mercados como meios para a acumulação de trabalho não remunerado (FEDERICI, 2017:144).

Diante do fato de os homens exercerem seu trabalho fora de casa e serem os responsáveis financeiros das famílias, as mulheres ficaram em um lugar de dependência econômica e subordinação em relação a eles, sendo as principais responsáveis pela manutenção da casa e criação de filhos/as.

Para que o sistema capitalístico funcione, o corpo da mulher precisa ser controlado. Assim, o primeiro ponto de análise é o corpo da mulher que gera e traz ao mundo indivíduos enxergados pelo Capitalismo como força de trabalho. Segundo, porque para que a nossa sociedade continue funcionando da forma como está, mulheres precisam continuar exercendo todo o trabalho com a casa, com a educação e o cuidado de crianças.

(...) na sociedade capitalista, o corpo é para as mulheres o que a fábrica é para os homens trabalhadores assalariados: o principal terreno de sua exploração e resistência, na mesma medida em que o corpo feminino foi apropriado pelo Estado e pelos homens, forçado a funcionar como meio de reprodução e a acumulação de trabalho. Neste sentido, é bem merecida a importância que adquiriu o corpo, em todos os seus aspectos - maternidade, parto e sexualidade - tanto dentro da teoria feminista quando na história das mulheres (FEDERICI, 2017:34).

As opressões sofridas por mulheres, que hoje entendemos como machismo, foram criadas e fortalecidas a partir do fim do feudalismo. Isso quer dizer que, sobretudo desde a Revolução Industrial, mulheres são socializadas para ocuparem o lugar de submissão, dentro do jogo de poder entre os gêneros.

Ainda na perspectiva do controle do corpo da mulher, a maternidade é um ponto de tensão que se apresenta nesses tempos de confinamento em casa. Logo, o debate sobre assuntos como maternidade compulsória, solidão materna, romantização da maternidade, entre outros, vem ganhando cada vez mais espaço nas discussões acadêmicas e nas redes sociais.

Produza como se não estivesse em casa, esteja em casa como se não fosse necessário produzir, limpe, esfregue, cozinhe, não, não, não, você NÃO vai cozinhar qualquer coisa. Legumes, verduras, tudo muito bem esterilizado com álcool gel. Seja uma boa mãe, acompanhe a lição das crianças enquanto trabalha, veja bem, tem aula na tv, tem inúmeras tarefas de seis páginas que não param de chegar no celular! (MELO, 2020:44).

Em tempos de pandemia a mulher estaria no lugar a ela destinado, o lar. O cuidado da casa e das crianças se refletem nas estatísticas sobre a guarda de filhos e filhas. O deferimento da guarda à mãe ainda corresponde à maioria dos casos no Brasil (IBGE, Estatística do Registro Civil, 2017), assim como o entendimento jurídico de que quando a criança é muito pequena ela 


\section{Nanduty}

ISSN:2317-8590

deve permanecer sob o cuidado exclusivo ou pelo menos principal da mãe. Essa visão parece estar ligada à crença de que existe um instinto materno, ideia refutada por Badinter (1985) que aponta uma variabilidade de sentimentos da mãe pelos/as filhos/as. O amor materno é algo que se adquire, não é um sentimento inerente à condição de mulher. Assim como os outros sentimentos humanos, o amor materno varia de acordo com as flutuações socioeconômicas e históricas. (Badinter, 1985).

Essa naturalização do amor materno parece ter provocado a desresponsabilização dos homens no que se refere aos cuidados dos/as filhos/as, especialmente na dissolução da relação conjugal. "A mulher não nasce apta a cuidar dos filhos, torna-se apta. O homem pode - e deve - passar pelo mesmo processo cultural para se tornar igualmente apto a este cuidado" (SCHENEEBELI e MEANDRO, 2014:178).

A família patriarcal, entendida como aquela em que o pai exerce a função de chefe ou autoridade maior do grupo familiar, e a mulher a que cuida da prole, parece ter ficado mais evidente durante a pandemia, apesar de todas as mudanças sociais das últimas décadas. $\mathrm{O}$ acúmulo de tarefas envolvendo os cuidados com a casa, os/as filhos/as e o trabalho aparentam ter trazido para a cena as desigualdades e assimetrias vivenciadas no cotidiano dessas famílias.

A live "Quais as novas configurações que a pandemia traz para parentalidade e trabalho?" traz a educadora Lua Barros, que optou por morar com o marido e filhos em uma cidade do interior de Minas Gerais e trabalhar de forma autônoma junto com o companheiro, em detrimento de uma carreira tida como "bem-sucedida". Lua fala sobre o desejo dela, ao ser mãe, de poder acompanhar o crescimento dos filhos sem que o trabalho fosse um impeditivo para isso. O entrevistador, Rodrigo Cunha, do Canal Humanos de Negócios, fala sobre a pesquisa que fez com empresários milionários para escrever um livro, na qual observou a infelicidade destes por não terem visto seus/suas filhos/as crescerem. Lua Barros conta sobre sua experiência pessoal e fala sobre o conceito de parentalidade positiva, baseado no conceito de Disciplina Positiva de Jane Nelsen, usando a comunicação não violenta de Marshall Rosenberg e o conceito de inteligência emocional como instrumentais. No vídeo a assimetria entre os gêneros é discutida, a educadora questiona o lugar do trabalho para homens e mulheres: enquanto homens precisam, por exemplo, inventar uma dor de barriga para levar o/a filho/a ao médico, a mãe arrisca perder o emprego para levá-lo quantas vezes forem necessárias, ou seja, o lugar do homem, apesar de também ser de sofrimento, é muito mais confortável em nossa sociedade patriarcal. A debatedora discute de forma crítica essa assimetria, avaliando que, 


\section{Nanduty}

ISSN:2317-8590

apesar de alguns homens estarem participando mais da vida dos/as filhos/as, ainda é muito incipiente diante da presença muito mais marcante da mulher nos cuidados diários com as crianças.

As duas próximas lives analisadas farão referência ao trabalho da mulher na ciência, discutindo a sobrecarga de trabalho no que se refere ao exercício profissional, a ser mulher e mãe em tempos de pandemia.

Na Aula Pública “ADUFRGS - Mulher, maternidade e trabalho em tempos de pandemia COVID-19”, Mariana Carneiro, partindo de sua trajetória como psicóloga-mãe-professora universitária e da ideia de Simone de Beauvoir de que basta uma crise para que os direitos das mulheres sejam questionados, traz a discussão da sobrecarga de trabalho das mulheres. De acordo com a aula do Sindicato de Professores Federal de Ensino Superior do Rio Grande do Sul (Adufrgs), com as psicólogas Mariana Moreira e Giana Frizzo, tanto os trabalhos informais afetados pela crise causada pela Pandemia, quanto $70 \%$ dos trabalhos na área de saúde são desempenhados por mulheres. Além disso, Moreira e Frizzo apontam que a sobrecarga das mulheres é também reflexo do fato de que famílias nunca tiveram que conviver tanto e por tanto tempo, o que contribui para exaustão das mulheres que historicamente já realizavam jornadas triplas e lidavam com a sobrecarga mental de organizar toda a estrutura familiar, sem o auxílio da escola ou outras redes de apoio.

Gaidargi-Garutti (2020) relata sobre o desafio de ser cientista e mãe, rompendo com o sistema machista da alta academia. O isolamento social evidenciou a questão arcaica do endereçamento, quase que exclusivo, dos cuidados parentais às mulheres, muitas vezes cortinado no cotidiano. As mães cientistas querem auxiliar seus filhos e filhas na elaboração da vivência deste momento difícil e ímpar para todas as pessoas, mas também reivindicam o direito de dar continuidade a suas atividades de pesquisa, que exige concentração e tempo. A necessidade de reinventar estratégias se faz imperativa, assim como em diversos momentos em que se está neste lugar de mãe e cientista.

Mães cientistas têm uma certa prática nisso, já passamos antes por uma reinvenção quando parimos e o mundo acadêmico passou a nos ver diferente. Aprendemos a pensar analiticamente mesmo presas em casa no pós-parto, quando os prazos nem sempre param. Descobrimos que a disponibilidade que tínhamos antes da maternidade muitas vezes pesou mais que nossa dedicação real. E passamos por adaptações o tempo todo, quando nos deparamos com a verdade de que a maternidade não é compreendida como deveria por muitos de nossos pares, que são filhos de alguém quando não são pais de alguém também (GAIDARGI-GARUTTI, 2020:48-49). 


\section{Nanduty}

ISSN:2317-8590

A live "Desafios para mulheres da pandemia Covid-19: reflexões no âmbito universitário", organizada pelo Grupo de Trabalho de Mulheres na Ciência, se propõe a debater a respeito das exigências de produtividade acadêmica e os critérios de avaliação dessa produção, analisando de que maneira esses dois fatores, da forma como estão estabelecidos atualmente, promovem disparidades de gênero e raça no rendimento profissional dentro das universidades. Isso porque as avaliações implementadas no meio acadêmico não levam em consideração como as particularidades das mulheres, assim como a de pessoas negras, se relacionam e afetam seus trabalhos e oportunidades de acesso/avanço na carreira universitária. As debatedoras do vídeo, todas professoras da Universidade Federal Fluminense (UFF), apresentam o cenário da pandemia como agravante de um cenário que já estava colocado em momento anterior, no qual mulheres, mulheres com filhos/as, mulheres negras têm uma disparidade de produtividade em comparação aos homens com filhos/as e sem filhos/as. A professora Andrea Latge fala que existe uma crença de que mulheres não podem ocupar as áreas exatas e tecnológicas e isso vai mantendo a mulher nas profissões de cuidado. Sinaliza também que quando a mulher decide ter filhos/as sua produção científica cai muito, pois precisa se dedicar aos cuidados destes e que por muitas vezes abandonam ou deixam de lado a vida acadêmica/profissional.

O jornal O Globo, no dia 04/10/20, publicou uma reportagem intitulada "Pandemia renova dilema entre trabalho e maternidade" que conta a experiência de Bibiana, 40 anos, que optou por pedir demissão, após seu chefe solicitar que ela trabalhasse cada vez mais na pandemia e se trancasse no quarto para que o filho de 2 anos não atrapalhasse suas reuniões de trabalho. Assim como Bibiana, muitas mulheres-mães estão confinadas com seus/suas filhos/as em casa, sem poder contar com o suporte da escola e de outros familiares para lidar com os cuidados dos/as filhos/as, sentindo-se sobrecarregadas e com dificuldades para conciliar as demandas pessoais, dos/as filhos/as, da casa e do trabalho.

A live "Reinventar| Parentalidade em construção: ser família em tempos de pandemia" é feita por duas mulheres com o objetivo de discutir a vivência da parentalidade antes e durante o período de pandemia. A conversa que é voltada para outras pessoas com vivências similares é mediada por uma psicóloga e uma arquiteta, que é responsável por compartilhar suas experiências de maternidade. Ao longo da conversa falam sobre a dificuldade de conciliar os cuidados com o/a filho/a e a rotina de trabalho, a falta que faz a rede de cuidado em meio a essa rotina e como dar conta do cuidado de si e também dos/as filhos/as. Por ser uma live muito voltada para refletir sobre a experiência da maternidade e o lidar dessa relação com as 


\section{Nanduty}

ISSN:2317-8590

dificuldades apresentadas diante da situação do isolamento social, em alguns momentos, a conversa cai numa naturalização das funções de cuidado a partir de divisões pautadas pela naturalização das relações desiguais de gênero

Para abrir um leque de análises preciosas acerca de gênero, tempo e cuidado, Fernandes (2018) usa como estrada a história de Débora, mulher negra, mãe de Pedro - nascido no início dos anos 2000 no município de Niterói. A autora nos mostra o quanto se confunde a batalha de mulheres mães por melhores condições de vida com a luta pela apropriação de tempos, subjetividades, pertencimentos e mobilidades. O tempo de "ficar com" a criança - cuidados necessários - concorre com o tempo de "correr atrás" - formas de viração para o sustento, na tentativa de "uma vida melhor". Tais conceitos temporais entremeiam o texto para mostrar a necessidade de desnaturalizar a articulação social dos corpos femininos aos cuidados, chamados por diversas autoras e autores pelo nome de care.

Fernandes (2018) destaca que separações conjugais trazem à baila privilégios, prejuízos e poderes, assim como também trouxe o efeito decorrente da pandemia, no qual parece ter ficado mais destacado o direcionamento da administração do lar às mulheres, na falta da rede de cuidados - escola, creche, familiares, atividades contraturno escolar etc. Na ausência desses espaços, a partir das lives, foi possível perceber que em muitas famílias, sem alternativas para o care infantil, as atividades laborais das mães acabaram sendo sacrificadas, primeiramente.

Podemos pensar no trabalho "quarentenal" do cuidado como condição para a manutenção da vida escolar, de atividades de contraturno, assim como a forma como foram reinventados os contatos sociais das crianças com familiares e afetos, isoladas em suas casas por um longo período.

Em “O ponto zero da revolução", Federici fala sobre o trabalho doméstico, atribuição feminina, romantizado ao longo de anos, como sustentáculo de toda maquinaria capitalista e afirma:

Dizer que queremos salários pelo trabalho doméstico é o primeiro passo para recusá-lo, porque a demanda por um salário faz nosso trabalho visível. Essa visibilidade é a condição mais indispensável para começar a lutar contra essa situação, tanto em seu aspecto imediato como trabalho doméstico quanto em seu caráter mais traiçoeiro como próprio da feminilidade (FEDERICI, 2019:47-48).

Fernandes (2018) destaca que as atividades de "fora" possuem maior visibilidade, sendo consideradas "trabalho", o que não acontece com as atividades de "dentro", do care, apesar de relativo reconhecimento atrelado a carga mental, emocional e laboral envolvidas. Federici 
(2019) enxerga o fato de que para o capitalismo são reconhecidos como trabalho somente o que o capital consegue mensurar em valor monetário.

Exigir salários para o trabalho doméstico é tornar visível o fato que nossa mente, nosso corpo e nossas emoções têm sido distorcidos em benefício de uma função específica, e que, depois, nos foram devolvidos sob um modelo ao qual todas devemos nos conformar para sermos aceitas como mulheres em nossa sociedade (FEDERICI, 2019:48).

Sendo assim, compreendemos que os presentes tempos de isolamento físico social, mas de intensificação de relações digitais, nos trouxe a oportunidade de colocar em análise a prática de cuidados com o espaço domiciliar e das crianças. Espaço este colado, capitalisticamente, à figura da mãe - como algo fundamental à sustentação da vida de uma forma global, assim como a emergência de construção de estratégias para reorganização do cenário na busca por equidade de direitos no âmbito da parentalidade.

Robert Stevenson traz às telas a vida de Mary Poppins (1964), uma governanta-babá fantástica que é contratada por uma família rica inglesa no início do século XX. Para manter todas as suas obrigações referentes aos cuidados da casa e das crianças em dia, manter o bom humor, estar disponível para mediar os conflitos familiares e ainda oferecer carinho, a protagonista lançava mão de elementos sobrenaturais em todo o enredo, o que nos faz pensar em que medida é humanamente possível dar conta de coisas tão intensas rotineiramente e ainda ter espaço para cuidados consigo.

Slimani (2018) em seu trágico romance "Canções de Ninar”, parte do avesso de Roberta Stevenson e dedica suas páginas à dureza e vulnerabilidade que sofrem as mulheres que dispensam sua vida a cuidar de famílias, que não as suas, na Paris contemporânea. Em um dos trechos da trama, em um diálogo das pessoas que a empregam com amigos e amigas, comparam Louise, a babá, com Mary Poppins, por não entenderem como uma mulher, humana, conseguia cuidar da casa com maestria de quem teria poderes sobrenaturais. Em uma outra passagem, a autora fala sobre as mãos pequenas de Louise:

Quanto mais o tempo passa, mais Louise se sobressai na arte de se tornar, ao mesmo tempo, invisível e indispensável. Myriam não telefona mais para avisar que vai se atrasar e Mila não pergunta mais quando mamãe voltará. Louise está lá, levando pela mão esse edifício frágil. Myriam aceita esses cuidados. A cada dia deixa mais tarefas a uma grata Louise. A babá é como essas silhuetas que, no teatro, mudam no escuro os objetos de uma cena. Elas tiram um divã, empurram uma coluna de papelão com a mão, assim como um painel de parede. Louise se move nas coxias, discreta e poderosa. É ela quem segura os fios transparentes sem os quais a magia não pode acontecer. (...) Olham para ela, mas não veem. É uma presença íntima, mas jamais familiar. Chega cada vez mais cedo, vai embora cada vez mais tarde (SLIMANI, 2018:49-50). 


\section{Nanduty}

ISSN:2317-8590

Neste momento, ninguém chega e ninguém sai. E às mulheres continua cabendo a sobrecarga de trabalho.

\section{CONSIDERAÇÕES FINAIS}

Passado um ano e meio da pandemia, muito há a ser dito, mas também muito há a ser revelado, desvelado, inventado, descoberto, fabricado, duvidado. Este texto pretendeu elencar algumas das questões que chamaram a atenção no campo das parentalidades, a partir de lives que pudemos assistir.

Embora tenhamos listado, como um possível tema, a vida escolar, ela não apareceu. Provavelmente pelo momento da pandemia em que as lives foram feitas, com as escolas públicas e privadas fechadas ainda, e a família tendo que substituir em casa o tempo que as crianças em geral estavam neste outro espaço. Na cartografia, seguimos rastros, passamos por cruzamentos, vamos e voltamos em diferentes direções. Não há neutralidade nem há hipóteses, curiosidade, desejo um dispor-se turbinam nosso caminhar.

A ausência de intermitência das relações familiares acontece em um tempo de se falar muito de si performaticamente, de termos uma janela para o mundo em tempo real, nossa única possibilidade de comunicação com o/a outro/a. São muitas as questões em torno de um velho e frequente tema: pais, mães, filhos, filhas. As lives que analisamos pouco falam de outros/as familiares, estão centradas nessas figuras, e sempre voltadas para o mesmo público, sem colocar em análise a diversidade de famílias que temos no Brasil. Quem fala e quem escuta são as mesmas pessoas: homens e mulheres cis, heterossexuais, brancos e brancas, de camadas médias. As poucas referências a famílias de outras classes sociais as associavam a danos neurológicos oriundos de um desenvolvimento infantil prejudicado ou a perspectivas assistencialistas. Classe social e cor da pele não eram mencionadas, apontando uma dificuldade ou uma impossibilidade de interseccionar, o que é certamente uma escolha política.

Tribunais de Justiça e escolas naturalizam a necessidade de se ensinar sobre o exercício da parentalidade a pais e mães. As "oficinas de parentalidade", as "escolas de pais" oferecidas pelos tribunais em todo o país têm como público homens e mulheres pobres. Estas lives chamam a atenção por serem dirigidas a pais e mães de camadas médias e altas. Será que a ausência da intermitência, ou a hiperconvivência, como chamou Maria Homem, exigiu este aprendizado? O que se buscava? O que se oferece? 


\section{Nanduty}

ISSN:2317-8590

Se apresentações em congressos científicos ou a publicação em periódicos, formas de escoar o conhecimento produzidos, exigem doutorado ou algum reconhecimento de notório saber para que a fala tenha legitimidade, o que vimos nessas lives foi um uso da linguagem para falar de si como suficientes, se for para revelar experiências de maternidade ou paternidade. Contar de si para romper barreiras, trazer proximidade.

Se é verdade que o home office interfere diretamente na vida profissional e na produtividade dos adultos, ainda que com efeitos bastante variados, como ressaltam Lemos et al (2020), sacoleja o casamento e pode aproximar os membros da família nuclear ou desgastar as relações, quando há crianças, elas são o foco. Como distrair as crianças, como fazê-las interagir com a professora e os/as amiguinhos/as, sobretudo se forem pequenas, através de uma tela, sem corridas, tombos, colo, foi um desafio. Para muitas famílias de camadas médias, que passaram a contar de outra forma com as atividades escolares, a dificuldade era como tornar-se a/o auxiliar de professora de 3o, 4o ano dando explicações complementares, acompanhando as tarefas assíncronas. Apesar da centralidade das crianças nessas cenas familiares, cuja grande preocupação era como se ocupar delas e/ou como entretê-las durante muitas horas todos os dias, elas não aparecem como sujeitos. Um paradoxo? Não aparecem como protagonistas, não são ouvidas para dizer o que sentem, do que precisam. As lives são sobre elas, mas constatações adultocêntricas, não se parte dos sentimentos ou opiniões delas.

Por mais que hoje, apesar de todas as mudanças, mais e mais homens participem dos cuidados da casa e da prole, e que nas camadas médias urbanas se conte com babás, empregadas domésticas e família extensa, ainda se associa fortemente cuidado à mulher e as mulheres têm experimentado uma sobrecarga nesses tempos de pandemia.

No entanto, todo este cenário pode servir também como uma oportunidade para se pensar como se deseja construir as relações de parentalidade, em suas intensidades, interações e convivência, quando o cotidiano voltar a incluir a vida externa à casa.

\section{REFERÊNCIAS}

ANDERSON, Chris. 2016. TED Talks: o guia oficial do TED para falar em público. Rio de Janeiro: Intrínseca.

BADINTER, Elizabeth. 1985. Um Amor Conquistado: o mito do amor materno. Rio de Janeiro, Nova Fronteira.

BARROSO, Ricardo; MACHADO, Carla. 2010. Definições, dimensões e determinantes da parentalidade. Pshycologia, Coimbra, 52 (1): 211-229. 
BONALUME, Bruna Carolina \& JACINTO, Adriana Giaqueto. 2019. Encarceramento juvenil: o legado histórico de seletividade e criminalização da pobreza. Revista. Katálysis, Florianópolis, 22(1):160-170, abr.

BRASIL. Constituição da República Federativa do Brasil de 1988. In: http://www.planalto.gov.br/ccivil_03/constituicao/constituicao.htm (acessado em: 02 de dezembro de 2020.

BRASIL. Lei $n^{o} 8.069$ de 13 de julho de 1990. In: http://www.planalto.gov.br/ccivil_03/leis/18069.htm (acessado em: 05 de maio de 2021).

BRONFENBRENNER, Urie. (2011). Bioecologia do desenvolvimento humano: tornando os seres humanos mais humano. A. Carvalho-Barreto (Trad.). Porto Alegre: Artmed. (Publicado originalmente em 2005).

CAMPOS, Maria Malta et al. 2014. Fulvia Rosemberg (1942-2014). Cadernos de Pesquisa, São Paulo, 44(153):760-775, jul./set.

CARVALHO, Rodrigo Saballa de. 2016. O investimento na formação do cidadão do futuro: a aliança entre economia e educação infantil como estratégia da governamentalidade contemporânea. Educação em revista, Belo Horizonte, 32(02): 229-253, abril-junho.

CASTRO, Lucia Rabello \& GRISOLIA, Felipe Salvador. 2016. Subjetivação pública ou socialização política? Sobre as articulações entre o "político" e a infância. Educ. Soc., Campinas, 37 (137):971-988, out.-dez.

DANTAS, Cristina Ribeiro Teixeira et al. 2019. "Repercussões da Parentalidade na Conjugalidade do Casal Recasado: Revelações das Madrastas". Psic.: Teor. e Pesq., Brasília, v. 35 , e3545.

FEDERICI, Silvia. 2017. Calibã e bruxa: mulheres, corpo e acumulação primitiva. São Paulo, Editora Elefante.

FEDERICI, Silvia. 2019. O ponto zero da revolução: trabalho doméstico, reprodução e luta feminista. São Paulo, Elefante.

FERNANDES, Camila. 2018. O tempo do cuidado: batalhas feministas por autonomia e mobilidade. In: Rangel, Everton; Fernandes, Camila \& Lima, Fátima. (Des) Prazer da norma. Rio de Janeiro, Papéis Selvagens, p.297-320.

FONSECA, Tania Maria Galli; NASCIMENTO, Maria Lívia. \& MARASCHIN, Cleci. 2012. Pesquisar na diferença: um abecedário. Porto Alegre, Sulina.

FÓRUM BRASILEIRO DE SEGURANÇA PÚBLICA. 2020. Nota técnica: Violência doméstica durante de CONdemia In: http://forumseguranca.org.br/publicacoes_posts/violencia-domestica-durante-pandemia-decovid-19/ (acessado em 07 de agosto de 2021).

FOUCAULT, Michel. 2008. Segurança, Território, População. São Paulo: Martins Fontes. GAIDARGI-GARUTTI, Alessandra Maria Martins. 2020. Mães cientistas. In: SOARES, Ana Carolina Eiras Coelho; CIDADE, Camilla de Almeida Santos \& CARDOSO, Vanessa Clemente (orgs.). Maternidades plurais: os diferentes relatos, aventuras e oceanos de mães cientistas na pandemia. Belford Roxo, Bindi Acadêmico, p. 48-50.

GUIZZO, Bianca Salazar; MARCELLO, Fabiana de Amorim \& Müller, Fernanda. (2020). A reinvenção do cotidiano em tempos de pandemia. Educação e Pesquisa, São Paulo, 46, e238077. Epub 10 de agosto de 2020.

HOMEM, Maria. 2020. Lupa da Alma: Quarentena revelação. São Paulo: Todavia, 2020.

IBGE, Estatísticas do Registro Civil 2017. Atualizado em 16/01/2019. In:https://biblioteca.ibge.gov.br/visualizacao/periodicos/135/rc_2017_v44_informativo.pdf (acessado em: 15 de outubro de 2020). 
LEMOS, Ana Heloísa da Costa; BARBOSA, Alane de Oliveira \& MONZATO, Priscila Pinheiro. 2020. Mulheres em home office durante a pandemia da covid-19 e as configurações do conflito trabalho-família. Rev. adm. empres., São Paulo, 60(6): 388-399, dez.

LIANG, T. 2020. Zhejiang University School of Medicine. Handbook of COVID-19: prevention and treatment. Paris, UNESCO.

LINHARES, Maria Beatriz Martins. 2015. Família e desenvolvimento na primeira infância: processo de autorregulação, resiliência e socialização de crianças pequenas. In: PLUCIENNIK, Gabriela Aratangue; LAZZARI; Márcia Cristina; CHICARO, Marina Fragata (Orgs.), Fundamentos da família como promotora do desenvolvimento infantil: parentalidade em foco. São Paulo: Fundação Maria Cecília Souto Vidigal, p.70-82.

LINHARES, Maria Beatriz Martins \& MARTINS, Carolina Beatriz Savegnago (2015). O processo da autorregulação no desenvolvimento de crianças. Estudos de Psicologia, Campinas, 32(2): 281-293.

LINHARES, Maria Beatriz Martins \& ENUMO, Sônia Regina Fiorim. 2020. Reflexões baseadas na Psicologia sobre efeitos da pandemia COVID-19 no desenvolvimento infantil. Estudos de Psicologia, Campinas, 37, e200089, june.

MADIGAN, Sheri; CYR, Chantal; EIRICH, Rachel; FEARON, R. M. Pasco; LY, Anh; RASH, Chrsitina; POOLE, Julia C.; ALINK, Lenneke. R. A. 2019. Testing the cycle of maltreatment hypothesis: meta-analytic evidence of the intergenerational transmission of child maltreatment. Developmental Psychopathology, 31(1):23-51.

MARTINS, E. Pandemia renova dilema entre trabalho e maternidade. Jornal O Globo. Rio de Janeiro: Caderno Economia, p. 29, 4 de outubro de 2020.

MARY POPPINS. 1964. Direção de Robert Stevenson. Estados Unidos: Walt Disney Pictures. $139 \mathrm{~min}$

MBEMBE, Achille. 2018. Necropolítica. São Paulo: n-1 edições.

MELO, Alessandra Aparecida de. 2020. Mãe, Mamãe, Mããããnhêeeeeeee: Produção Acadêmica, Maternidade e Pandemia. In: SOARES, Ana Carolina Eiras Coelho; CIDADE, Camilla de Almeida Santos \& CARDOSO, Vanessa Clemente (orgs.). Maternidades plurais: os diferentes relatos, aventuras e oceanos de mães cientistas na pandemia. Belford Roxo: Bindi Acadêmico, p. 44-47.

NASCIMENTO, Maria Lívia do, CUNHA, Fabiana Lopes da \& VICENTE, Laila Maria Domith. 2008. A desqualificação da família pobre como prática de criminalização da pobreza. Revista Psicologia Política, 7(14).

PASSOS, Eduardo. \& BARROS, Regina Benevides. 2010. Por uma política da narratividade. In: PASSOS, Eduardo; KASTRUP, Virgínia; ESCÓSSIA, Liliana da. (orgs) Pistas do método da cartografia: pesquisa-intervenção e produção de subjetividade. Porto Alegre, Sulina, p.150 -171 .

QUE HORAS ELA VOLTA? (2015). Direção de Anna Muylaert: África Filmes e Globo Filmes. 114 min.

ROLNIK, Suely. 1989. Cartografia Sentimental. São Paulo, Estação Liberdade.

ROMA. 2018. Direção de Alfonso Cuarón. México, Estados Unidos: Netflix. 135 min.

ROSA, Gabriel Arthur Marra; SANTOS, Benedito Rodrigues dos; FALEIROS, Vicente de Paula. 2016. Opacidad de las fronteras entre real y virtual en la perspectiva de los usuarios del Facebook. Psicologia USP, São Paulo, 27(2): 263-272.

ROSEMBERG, Fúlvia. 1976. Educação para quem? Revista Ciência e Cultura, Canoas, 28(12):1466-1471. 
SCHENEEBELI, Fernanda Cabral Ferreira \& MEANDRO, Maria Cristina Smith. 2014. Com quem as crianças ficarão? Representações sociais da guarda dos filhos após a separação conjugal. Psicologia \& Sociedade, São Paulo, 26 (1): 175-184.

SILVA, Beatriz Amorim de Azevedo e \& GRILLO, Sheila Vieira de Camargo. 2019. Novos percursos da ciência: as modificações da divulgação científica no meio digital a partir de uma análise contrastiva. Bakhtiniana, Rev. Estud. Discurso, São Paulo, 14(1):51-73, mar.

SILVA, Isabela Machado da; SCHMIDT, Beatriz; LORDELLO, Silvia Renata; NOAl, Débora da Silva; CREPALDI, Maria Aparecida \& WAGNER, Adriana. 2020. As relações familiares diante da COVID-19: recursos, riscos e implicações para a prática da terapia de casal e família. Pensando famílias, Brasília, 24(1): 12-28.

SLIMANI, Leila. 2018. Canção de ninar. São Paulo, Planeta.

SOARES, Ana Carolina Eiras Coelho; CIDADE, Camilla de Almeida Santos \& CARDOSO, Vanessa Clemente (orgs.). 2020. Maternidades plurais: os diferentes relatos, aventuras $e$ oceanos de mães cientistas na pandemia. Belford Roxo, Bindi Acadêmico.

SOCIEDADE BRASILEIRA DE PEDIATRIA. 2017. Manual de Orientação Departamento Científico de Pediatria do Desenvolvimento e Comportamento: o papel do pediatra na prevenção do estresse tóxico na infância. $\mathrm{N}^{\mathrm{o}} 3 . \quad \mathrm{In}$ : https://www.sbp.com.br/fileadmin/user_upload/2017/06/Ped.-Desenv.-Comp.-MOrient-Papelpediatra-prev-estresse.pdf (acessado em 07 de agosto de 2021).

\section{REFERÊNCIAS lives}

1. Humanos de Negócios. (2020, 14 de maio). Live: Quais as novas configurações que a pandemia traz para parentalidade e trabalho? [Video]. Youtube. https://www.youtube.com/watch?v=6ttcq3y2j0U

2. Lapsivi - Laboratório de Psicanálise. (2020, 27 de julho) Lapsivi Discute: Parentalidade e infância em tempos de pandemia [Video]. Youtube. https://www.youtube.com/watch?v=11036cz40GA

3. Comunidade Intermunicipal do Ave (2020, 28 de maio). Desafios à parentalidade em tempos de coronavírus: Regras e Rotinas [Video]. Youtube. https://www.youtube.com/watch?v=14gygUcSLxk

4. Amaná Educacional - Regina Shudo. (2020, 15 de julho). Live - A pandemia como possibilidade de reconexão entre escola $x$ família [Video]. Youtube. https://www.youtube.com/watch?v=ym73N5qkMuM

5. Adufrgs. (2020, 17 de junho). Aula Pública ADUFRGS - Mulher, maternidade e trabalho em tempos de pandemia COVID-19 [Video]. Youtube. https://www.youtube.com/watch?v=N7nKMcEHJaM

6. Instituto Casagrande. (2020, 4 de agosto). Reflexões sobre a primeira infância em tempos de pandemia [Video]. Youtube. https://www.youtube.com/watch?v=-dnWBdLoUY

7. Casa do Saber. (2020, 22 de junho). Amor e Desamor na Pandemia, com Vera Iaconelli e Mario Vitor Santos [Video]. Youtube. https://www.youtube.com/watch?v=9nQAThZ9q24\&ab_channel=CasadoSaber

8. AEC Vizela. (2020, 9 de junho). Ser mãe e ser pai na pandemia covid-19 parentalidade mindful [Video]. Youtube. https://www.youtube.com/watch?v=0LzKQa83tZE 
9. Comunidade Intermunicipal do Ave. (2020, 21 de maio). Desafios à parentalidade em tempos de coronavírus: Dicas de apoio ao estudo em casa [Video]. Youtube. https://www.youtube.com/watch?v=pFSbMkWI-cw

10. Nasce Saúde. (2020, 8 de maio). LIVE: Gestação, estresse e pandemia: que tal uma nova perspectiva? Por Tiane Salum, obstetra [Video]. Youtube. https://www.youtube.com/watch?v=N4x9cQjld9Y

11. Canal da Ansiedade - Terapeuta Elsie Herber. (2020, 22 de março). Pandemia e ansiedade: como acolher as crianças [Video]. Youtube. https://www.youtube.com/watch?v=f8dJaMpOom4

12. Comunidade Intermunicipal do Ave. (2020, 18 de junho). Desafios à parentalidade em tempos de coronavírus: Brincar [Video]. Youtube. https://www.youtube.com/watch?v=FYnUnOLx-cw

13. Comunidade Intermunicipal do Ave. (2020, 4 de junho). Desafios à parentalidade em tempos de coronavirus: Estratégias para ajudar as crianças a acalmar [Video]. Youtube. https://www.youtube.com/watch?v=qA2pjyz8xtw

14. Unitevê - TV Universitária da UFF. (2020, 20 de julho). AO VIVO - Desafios para mulheres da pandemia Covid-19: reflexões no âmbito universitário [Video]. Youtube. https://www.youtube.com/watch?v=l1kFWaDUeOg

15. ANUP Oficial. (2020, 30 de junho). Webinar: Desafio Universitário pela Primeira Infância - Fortalecimento da Parentalidade [Video]. Youtube. https://www.youtube.com/watch?v=oRBwEmLpyRc

16. Reinventar Integrando seres e saberes. (2020, 7 de setembro). Live Reinventar | Parentalidade em construção: ser família em tempos de pandemia [Video]. Youtube. https://www.youtube.com/watch?v=-59b2jQ11C4

17. Casa do Saber. (2020, 30 de março). Pais e Filhos: Como conviver nos tempos de Pandemia, com Adriana Friedmann e Mario Vitor Santos [Video]. Youtube. https://www.youtube.com/watch?v=AdSji7lmMas

18. Comunidade Intermunicipal do Ave. (2020, 14 de maio). Desafios à parentalidade em tempos de coronavírus: Como prevenir o burnout parental? [Video]. Youtube. https://www.youtube.com/watch?v=EeqyaU9L3xU

19. Inconsciente Coletivo Entrevista. (2020, 22 de junho). Como educar xs filhxs em tempo de pandemia e pandemônio - com Vera Iaconelli [Video]. Youtube. https://www.youtube.com/watch?v=rnL-FyQTQGI

20. Clínica e Instituto Horizontes. (2020, 17 de julho). EVENTO: Sobre bebês e crianças em tempo de pandemia [Video]. Youtube. https://www.youtube.com/watch?v=VOXTGjvnyOQ

21. Comunidade Intermunicipal do Ave. (2020, 2 de julho). Desafios à parentalidade em tempos de pandemia: Comunicação positiva e mensagens na primeira pessoa [Video]. Youtube. https://www.youtube.com/watch?v=Vyw1AlUYZq8

22. IERBB MPRJ. (2020, 6 de maio). IERBB/MPRJ CONECTA: Primeira Infância em Tempos de Pandemia [Video]. Youtube. https://www.youtube.com/watch?v=1KEVJYS5V8g

23. Queiroz, T. (2020, 15 de julho). Impactos da Pandemia nos Filhos e Pais - Paizinho, Virgula! [Video]. Youtube. https://www.youtube.com/watch?v=jwVeWrTEgCc

24. Gomes, L. (2020, 22 de abril). Parentalidade e Quarentena [Video]. Youtube. https://www.youtube.com/watch?v=tdDN34v1AJ4 


\section{Nanduty}

ISSN:2317-8590

25. Maziero, F. (2020, 23 de março). Durante a quarentena provocada pelo coronavírus, como fica o direito de visita? [Video]. Youtube.

https://www.youtube.com/watch?v=38Nu9TRMlu8\&

26. Homem, M. (2020, 31 de julho). MARIA HOMEM: HIPERCONVIVÊNCIA EM CASA [Video]. Youtube. https://www.youtube.com/watch?v=YLNxbfMseXA 